\title{
CLINICAL PROFILE OF HEMOPHILIA PATIENTS: A CROSS SECTIONAL STUDY AT A TERTIARY CARE CENTER IN INDIA
}

\author{
Ram Sunder Sharma ${ }^{1}$, Arun Kumar Arya ${ }^{2}$ \\ ${ }_{1}^{1}$ Post Graduate Student, Department of Paediatrics, G. S. V. M. Medical College, Kanpur, Uttar Pradesh. \\ ${ }^{2}$ Assistant Professor, Department of Paediatrics, G. S. V. M. Medical College, Kanpur, Uttar Pradesh.
}

\begin{abstract}
The study was designed to determine clinical profile of haemophilia patients in North India. In this cross-sectional study, we obtained family history and clinical profile of 54 diagnosed severe haemophilia patients attending Haemophilia Treatment Centre, Children Hospital LLR Hospital, Kanpur, India, for factor replacement therapy. We also obtained blood samples to investigate for hepatitis B, HIV. In study we observed that majority of the patients having their first presentation in their infancy (70.3\%) and median age of first presentation was 11 months of age. Though haemophilia is a genetic disorder, family history was negative in majority of patients; (70.3\%) subcutaneous tissue was most frequent site for initial bleeds, but as age advances joints become frequently involved and hemarthrosis was commonest complication affecting 79.6\% patients. Most common involved joint was knee joint $(53.7 \%)$. This hemarthrosis is the major cause of morbidity affecting quality of life of patients. Due to cost of treatment, many times we have to transfuse blood and blood products which may lead to Transfusion Transmitted Infection (TTI). In our study prevalence of TTI was $1.85 \%$ and $3.70 \%$ for HIV and Hep. B respectively. We also observed that there was time lag of $>1$ month in $16.5 \%$ cases between onset of symptom and definitive diagnosis, which shows lack of awareness among doctors in community. In view of this high morbidity and TTIs, we emphasize the free availability of factor concentrates and prophylactic treatment should be followed instead of palliative treatment.
\end{abstract}

\section{KEYWORDS}

Hemophilia, India.

HOW TO CITE THIS ARTICLE: Ram Sunder Sharma, Arun Kumar Arya. "Clinical Profile of Hemophilia Patients: A Cross Sectional Study at a Tertiary Care Center in India." Journal of Evolution of Medical and Dental Sciences 2015; Vol. 4, Issue 98, December 07; Page: 16350-16352, DOI: $10.14260 /$ jemds/2015/2416

\section{INTRODUCTION}

Hemophilia A (Factor VIII deficiency) and hemophilia B (Factor IX deficiency) are the most common and serious congenital coagulation factor deficiencies. These are X linked diseases. Both factors take part in the intrinsic pathway of blood coagulation and affected individuals have severe, moderate and mild forms of the diseases defined by factor plasma levels of $1 \%$ or less, $2 \%$ to $5 \%$ and $6 \%$ to $40 \%$ respectively. ${ }^{1}$

The prevalence of hemophilia A is 1 in 5000 male live births and that of hemophilia B is 1 in $30,000 .^{2}$

Signs and symptoms can vary from intracranial Hemorrhage to easy bruising, intramuscular hematomas and hemarthrosis begin when child "Begins to cruise." Although hallmark of hemophilic bleeding is hemarthrosis, the earliest joint hemorrhage appears most commonly in the ankle. ${ }^{1}$

Many mild cases (FVIII activity $>5 \%$ ) may not be diagnosed until later in life after trauma or surgery or not at all, most moderate (FVIII 1\%-5\%) and severe (FVIII <1\%) cases are likely known at birth or early in life. ${ }^{3}$

\section{METHOD}

\section{Study Design}

A cross-sectional study was carried out at Hemophilia Treatment Centre, Children Hospital, G.S.V.M. Medical College, Kanpur, Uttar Pradesh (India), which is a Tertiary Care Hospital.

\section{Study Group}

The study group consists of 54 diagnosed cases of hemophilia

Financial or Other, Competing Interest: None.

Submission 17-11-2015, Peer Review 18-11-2015,

Acceptance 27-11-2015, Published 07-12-2015.

Corresponding Author:

Dr. Ram Sunder Sharma

F-88, Harishankarpuram

Gwalior, Madhya Pradesh, India.

E-mail: dr.ramsundersharma@gmail.com

DOI:10.14260/jemds/2015/2416 admitted in Hemophilia Treatment Centre at a Tertiary Care Center in India during January 2012 to July 2013.

\section{Inclusion Criteria}

All patients attending Hemophilia Treatment Centre for factor replacement therapy.

\section{METHODOLOGY}

Clinical record and family history of all patient of severe hemophilia attending Hemophilia Treatment Center was collected and evaluated for age at first bleed, frequency of bleeding, site, family history of bleeding, other associated symptoms and complications.

Patients were also asked for any delay between onset of first bleeding and definite diagnosis were made to assess awareness amongst doctors about hemophilia.

Patients were also screened for any transfusion transmitted diseases.

\section{RESULT}

We have drawn the following results from this study

1. Majority of the patients having their first presentation in their infancy $(70.3 \%)$. Median age of first presentation was 11 months of age. Very few patients (4\%) have their first presentation after age of 10 years.

2. Prevalence of hemophilia $A$ is more as $90.7 \%$ patients were of hemophilia A and only $9.3 \%$ cases were of hemophilia B.

3. The family history was negative in majority of patients; $70.3 \%$ patients do not have any family history of hemophilia as suggested by some previous studies. Only $29.7 \%$ patients had family history of hemophilia.

4. History of consanguineous marriage was absent in majority of patients, though consanguineous marriage is a risk factor for genetic diseases.

5. Most common site of first bleeding was subcutaneous tissue in all patients. In $<6$ months of age most common site was also subcutaneous bleeding $45 \%(9 / 20)$. In age group 6-12 month out of 19 patients, 6(31.5\%) present with subcutaneous bleeding and 5 patients $(26.3 \%)$ present with joint bleeding because as child begins to 
cruise hemarthrosis develops.Frequency of bleeding in majority of patients was 11-15 per year. But patients did not have factor replacement each time might be because minor bleeding episodes were not reported immediately and unavailability of factor concentrate each and every time in Indian context. (Table -1).

6. Hemarthrosis was commonest complication affecting $79.6 \%$ patients. Most common involved joint was knee joint (53.7\%). (Table -2).

7. Most common presenting symptom was joint bleeding (57\%) followed by gum bleeding (22\%).

8. Two patients were expired due to intracranial haemorrhage $(2 / 54 ; 3.7 \%)$.

9. Transfusion transmitted infection (HIV, HbsAg) were positive in $1.85 \%, 3.70 \%$ patients respectively.

10. There was time lag of $>1$ week in $18.5 \%$ patients for making definitive diagnosis. This reflects the lack of awareness in doctors towards hemophilia.

\section{DISCUSSION}

This study was undertaken in the Hemophilia Treatment Centre, at a Tertiary Care Centre in India. The objectives of this study were to assess clinical and familial profile of hemophilia A and B; 54 patients of severe hemophilia of pediatric age group (0-18 years) who were admitted in Hemophilia Treatment Centre during period of January 2012 to July 2013 were analyzed. Treatment profile of patients were analyzed and blood samples were collected for investigations. Investigations done were Prothrombin Time (PT), Activated Partial Thromboplastin Time (aPTT), factor VIII level, von Willebrand assay.

As per a study done by Li. ${ }^{4}$ et al. (2013), the median age at first bleeding was 1 year (Range: 0-35 years). The percentages of patients with first bleeding age $<1$ year, $\geq 2$ years and $\geq 6$ years were $44.3 \%(94 / 212), 34.4 \%(73 / 212)$, and $10.8 \%(23 / 212)$ respectively.

In our study median age at $1^{\text {st }}$ bleeding was 10 months and age wise percentage of $1^{\text {st }}$ bleeding at $0-6$ months; 6 months- 1 year; $1-2$ years; $2-5$ year; $5-10$ years; $>10$ years was $37 \%(20 / 54), 33 \%(18 / 54), 11 \%(6 / 54), 4 \%(2 / 54)$, $11 \%(6 / 54), 4 \%(2 / 54)$ respectively. Results in our study coincides with other studies done previously. (Table - 3).

Though hemophilia is a genetic disorder, only $29.7 \%$ cases show positive family history of hemophilia opposed to other studies done previously, in which positive family history is seen in $50 \%-70 \%$ of cases. It might be due to intrachromosomal inversions involving introns 1 and 22 of the factor VIII gene, deletions, insertions, missense or nonsense point mutations or abnormal splicing. (Table - 4).

In our study, we observed that $3.7 \%$ patients were HBsAg positive and one patient (1.8\%) was HIV positive. Factor concentrates are costly and not available every time, so due to unavailability of factor concentrates many times we have to control bleeding with blood products, so due to multiple transfusions there are chances of transfusion transmitted infections.

Stachnik. ${ }^{5}$ (2010) observed that bleeding patterns seen in individuals with hemophilia vary with age; 15 initial bleeding episodes among neonates with severe hemophilia include prolonged bleeding from circumcision and head or intracranial bleeding; 15 infants between 1 and 6 months of age may experience soft tissue bleeding or bruising. As mobility increases with age, joint bleeding may be seen. In older children and adults, the joints are the most common site of spontaneous bleeding - referred to as hemarthrosis - and account for $70 \%$ to $80 \%$ of bleeding episodes. The knees (45\%), elbows (30\%), and ankles (15\%) are the most frequently affected; 13 bleeding can also occur in muscles, soft tissues or in the Central Nervous System (CNS).
In our study, $37 \%(20 / 54)$ patients presents between 0 6 month of age. In this age group, most common site of $1^{\text {st }}$ bleeding was subcutaneous bleeding; 9 patients having their $1^{\text {st }}$ bleeding as subcutaneous bleeding in this age group followed by bleeding from umbilicus $15 \%(3 / 20)$; circumcision $15 \%(3 / 20)$; gum bleeding $10 \%(2 / 20)$; joint bleeding $10 \%(2 / 20)$ and skin trauma 5\%(1/20). Overall most common site of $1^{\text {st }}$ bleeding was subcutaneous bleeding; $37 \%(20 / 54)$ followed by gum, joint and skin bleeding. As mobility increases, frequency of joint bleeding increases. In our study, annual bleeding frequency is $10-15$ per year in majority of patients, but factor concentrate was not available every time, so patients were less frequently exposed to factor concentrates.

As in other previous studies, most frequent site of bleeding was joint bleeding. Our study also shows that joints $75.9 \%(41 / 54)$ was most frequent site of bleeding having maximum involvement of knee joint $54 \%(29 / 54)$. Other joints were less frequently involved.

There was time lag of $>1$ month in $16.5 \%$ cases between onset of symptom and definitive diagnosis. It shows that there is lack of awareness about disease among doctors lead to delay in diagnosis. Doctors should keep high index of suspicion if any child presented with soft tissue or joint bleed.

\section{REFERENCES}

1. Kliegman RM, Stanton BF, GemeIII JWS, Schor NF, Behrman. Nelson textbook of pediatrics 19th edition 2011; p. 1699-1702.

2. Franchini M, Mannucci PM. Past, present and future of hemophilia: a narrative review. Orphanet J Rare Dis 2012;7:24.

3. Jarres. Current Controversies in the Formation and Treatment of Alloantibodies to Factor VIII in Congenital Hemophilia A. ASH Education Book. December 10, 2011 vol. 2011 no. 1 407-412.

4. Li H, Sun J, Zhou X, Liu Y, Song X, Ma Q. Clinical predictors for the phenotypic heterogeneity of severe hemophilia A in China. Nan Fang Yi Ke Da Xue Xue Bao.

2013 Mar; 33(3):424-7.

5. Stachnik J. Hemophilia. Etiology, complications, and current options in management. British Journal of Haematology 2010; Vol 111, Issue 1.

\begin{tabular}{|c|c|c|}
\hline Frequency Per Year & Cases & $\mathbf{\%}$ \\
\hline $1-10$ & 9 & 16.6 \\
\hline $11-15$ & 38 & 70.4 \\
\hline$>15$ & 7 & 13 \\
\hline Total & $\mathbf{5 4}$ & $\mathbf{1 0 0}$ \\
\hline Table 1: Bleeding Frequency Per Year \\
\hline
\end{tabular}

The above Table shows that majority of patients (70.4\%) presented to us had bleeding frequency of 11-15 per year.

\begin{tabular}{|c|c|c|}
\hline Site & No. of Cases & \% \\
\hline Knee joint & 29 & 53.7 \\
\hline Soft tissue & 9 & 16.6 \\
\hline Elbow joint & 5 & 9.40 \\
\hline Gum & 4 & 7.40 \\
\hline Ankle joint & 3 & 5.5 \\
\hline Hip joint & 2 & 3.7 \\
\hline >1 joint & 2 & 3.7 \\
\hline Total & $\mathbf{5 4}$ & $\mathbf{1 0 0}$ \\
\hline \multicolumn{2}{|c|}{ Table 2: Most Common Site of } \\
Bleeding (Target Joint) \\
\hline
\end{tabular}

The above Table shows that knee is most common site of repetitive bleeding and hemarthrosis is most common presenting symptom. 


\begin{tabular}{|c|c|c|}
\hline Age Group & No. of Cases & $\%$ \\
\hline $0-6$ months & 20 & 37 \\
\hline $6-12$ months & 18 & 33 \\
\hline $1-2$ years & 6 & 11 \\
\hline $2-5$ years & 2 & 4 \\
\hline $5-10$ years & 6 & 11 \\
\hline$>10$ years & 2 & 4 \\
\hline Total & 54 & 100 \\
\hline \multicolumn{3}{|c|}{$\begin{array}{c}\text { Table 3: Age Group of Patients at } \\
\text { Time of } 1^{\text {st }} \text { Presentation }\end{array}$} \\
\hline
\end{tabular}

\begin{tabular}{|c|c|c|}
\hline Family History & No. of Cases & \% \\
\hline Positive & 16 & 29.7 \\
\hline Negative & 38 & 70.3 \\
\hline Total & $\mathbf{5 4}$ & $\mathbf{1 0 0}$ \\
\hline \multicolumn{2}{|c|}{ Table 4: Family History of Hemophilia } \\
\hline
\end{tabular}

